\title{
Fusion legislation and forensic psychiatry: the criminal justice provisions of the Mental Capacity Act (Northern Ireland) 2016
}

\author{
Philip Campbell \& Keith Rix
}

\begin{abstract}
SUMMARY
Fusion legislation is the latest in a long line of reforms in mental health law that have sought to increase patient autonomy. It has not been without controversy, having been proposed and rejected in various jurisdictions throughout the UK and internationally, while causing considerable debate in the academic literature. This article considers some of the history and debate, along with the criminal justice provisions of the first piece of fusion legislation internationally, the Mental Capacity Act (Northern Ireland) 2016, and their potential implications.
\end{abstract}

\section{LEARNING OBJECTIVES}

- Understand the history of fusion legislation in the UK and internationally

- Understand the advantages and disadvantages of fusion legislation

- Understand the Mental Capacity Act (Northern Ireland) 2016 criminal justice provisions

\section{DECLARATION OF INTEREST}

None.

Questions of capacity, or whether a person is able to make their own decision, have been pondered in law at least since the 19th-century testamentary capacity of Banks v Goodfellow (1870). Decision-making capacity has been a fluid and evolving concept, with different criteria being used depending on the decision, and changes in the test for decision-making capacity taking place in successive case law and statute. In tandem with changes in the concept of decision-making capacity, mental health law in the UK has evolved from providing purely involuntary powers for the detention and treatment of the mentally ill to the introduction of voluntary admission to psychiatric facilities under the Mental Treatment Act 1930 and, in the past few decades, greater protections for those detained on an involuntary basis.
There have also been multiple attempts to incorporate a capacity-based approach to mental health law and consent to psychiatric treatment over the past 60 years, both in the UK and internationally (Applebaum 2010). These attempts have been somewhat controversial, with proponents arguing that a capacity-based approach would promote patient autonomy and reduce discrimination (Szmukler 2010), and opponents arguing that people with mental illnesses need specific legislation for the good of themselves and the public (Applebaum 2010). Legislators in most jurisdictions rejected a purely capacity-based approach to mental health law, with some opting for parallel legislation and others incorporating a softer test of incapacity into their mental health legislation.

Northern Ireland, in 2016, became the first jurisdiction to enact a single capacity-based legal framework to legislate for the involuntary treatment of all in society, including the mentally ill. The Mental Capacity Act (Northern Ireland) 2016 (MCA(NI)) repeals separate mental health legislation. Such an approach has been termed 'fusion legislation', as it fuses together mental health legislation and mental capacity legislation. No other country or jurisdiction has fully embraced this approach to the treatment of people with mental disorders. It is notable that Northern Ireland, given its history of civil conflict, has become the first jurisdiction to adopt such an approach. Some commentators have observed that countries or provinces which have experienced discrimination or civil strife take the need for just and non-discriminatory mental health legislation most seriously (Fistein 2009).

This article sets out the historical context of fusion legislation in the UK and internationally, considers the arguments for and against such an approach, and describes the principal provisions of Part 10 of the MCA(NI), which are the 'criminal justice' provisions, along with some key definitions and the potential impact of the legislation.
ARTICLE

Philip Campbell is a consultant psychiatrist based in Northern Ireland. He has been awarded a Master of Laws with distinction in mental health law. Keith Rix is an honorary consultant forensic psychiatrist with Norfolk and Suffolk NHS Foundation Trust and Visiting Professor of Medical Jurisprudence at the University of Chester, where he is involved with its MSc in Medicolegal Practice. He is an elected Honorary Fellow of the Faculty of Forensic and Legal Medicine of the Royal College of Physicians.

Correspondence Dr Philip Campbell, Bluestone Unit, Craigavon Area Hospital, 68 Lurgan Rd, Portadown, Craigavon BT63 500, UK. Email: philcampbell@doctors.net.uk

\section{Copyright and usage} (C) The Royal College of Psychiatrists 2018 


\section{A brief history of moves towards capacity- based mental health law}

Professional groups in the USA have unsuccessfully recommended a capacity-based approach to mental health law since the mid-20th century. Legislators appear to have rejected a capacity-based approach because of concerns that it could broaden the scope of commitment to hospital and because of concerns for public safety in cases where a mentally disordered person retains capacity but poses a risk to others (Applebaum 2010). Repeated attempts to incorporate such an approach into UK mental health legislation over the past few decades have mostly failed for the same reasons. The UK government rejected the Richardson Committee's (Department of Health 1999) recommendation to incorporate a capacitybased criterion into involuntary treatment of people with mental disorders, reasoning that it would broaden the scope of the legislation (Gledhill 2010). The Scottish Executive opted to incorporate a softer incapacity test of 'a significant impairment of decision making caused by the disorder' as a criterion for involuntary treatment, following the review of mental health legislation reported by the Millan Committee (Scottish Executive 2001) and the MacLean Committee (Scottish Executive 2000). However, a capacity-based approach was not incorporated into criminal justice provisions because of concerns for public safety (Gledhill 2010).

The MCA(NI) is the first piece of legislation to fully embrace a capacity-based approach to the involuntary treatment of all in society, including those with mental disorders.

\section{The advantages and disadvantages of fusion legislation}

The advantages of fusion legislation can be argued on ethical, clinical and legal grounds. Proponents of fusion legislation argue that the ethical advantages of such an approach include the protection of patient autonomy and the removal of discriminatory mental health legislation (Szmukler 2010). The argument that existing mental health law is discriminatory is made on the basis that patients' autonomy is not respected in the same way as in the rest of medicine and that people with mental disorders are the only group in society who are subject to preventive detention on the basis of risk alone, without any offence having been committed (Szmukler 2010). A clinical argument for fusion legislation is that an assessment of capacity to consent to treatment focuses on what is most relevant to a treatment decision, rather than wider notions of the presence of mental disorder and risk to self and others (Szmukler 2010). A clear legal advantage of fusion legislation is the removal of the interface between mental health legislation and mental capacity legislation. Another legal advantage of fusion legislation is that it appears to be more compliant with the United Nations Convention on the Rights of Persons with Disabilities (CRPD) (United Nations 2006) than existing mental health legislation, which some have argued is non-compliant with its Article 4 (no discrimination on the basis of disability) and Article 14 (no deprivation of liberty on the basis of disability) (Szmukler 2014).

The disadvantages of fusion legislation can also be argued on ethical, clinical and legal grounds. A key ethical argument against fusion legislation is that an increase in patient autonomy could come at the expense of beneficence (Burns 2010). Furthermore, in theory, there could be an increased risk of harm to the public in cases where a person is capable of making decisions in relation to treatment but remains a risk to others because of mental disorder (Gledhill 2010). Opponents of fusion legislation have argued that assessment of capacity in relation to mental disorder is unsuitable as a basis for making decisions in clinical practice. Cases in which a person is capable of making treatment decisions but poses a risk of suicide are of particular concern. Assessment of capacity has also been described as a narrow test that is inherently unsuitable for the complex and subtle forms of incapacity that may arise in mental illness (Burns 2010). Furthermore, assessments of capacity are decision specific and it is likely that multiple decisions will arise in relation to any episode of treatment. A legal argument against fusion legislation is that such an approach is non-compliant with Article 12 of the CRPD, which requires that persons with disabilities enjoy legal capacity on an equal basis with others in all aspects of life. However, attempts can be made to satisfy CRPD Article 12 by a statutory statement that fusion legislation applies to all regardless of disability, as has been done in the MCA(NI). A concerning criticism that fusion legislation is 'astonishingly illiberal' (Kelly 2016: p 101) has been made on the grounds that it increases the scope of legislation to restrict the liberty of people who may not have fallen under the remit of mental health legislation. Such people include those with mental disorders living in the community and those with 'physical disorders' who lack decision-making capacity (Kelly 2016). Be that as it may, many people in those circumstances may have had restrictions of liberty without the protection and reviews afforded by a formal statutory approach.

\section{The Mental Capacity Act (Northern Ireland) 2016}

The MCA(NI) is an extensive piece of legislation. It consists of 15 parts, 308 sections and 11 schedules. 
Part 1 contains the principles of the Act. Key principles include a presumption of capacity, an adherence to functional capacity assessments, that acts or decisions are in a person's best interests, and an emphasis on supportive decision-making measures. Part 2 provides a protection from liability for individuals doing acts to, or deciding on behalf of, a person lacking capacity (section (s.) 9). It contains general safeguards to protect the person's right to make their own decision, including provisions for a lasting power of attorney and the protection of advance decisions (ss. 10-11). There are additional safeguards to protect the person, including a requirement for formal assessments of capacity, authorisation of measures from a Trust panel, consultation with a nominated person, a requirement for second opinions, and a statutory role for independent mental capacity advocates (ss. 13-35). The general trend is that more rigorous additional safeguards are required for more serious interventions, such as depriving a person of their liberty or the provision of involuntary treatment with serious consequences. Box 1 sets out the principles of the Act and the main provisions of Part 2.

Box 2 sets out the Part 10 provisions for people in the criminal justice system. Guardianship orders are not included in the new legislation. Although there are powers for deprivation of liberty or transfer from prison to hospital regardless of capacity, treatment decisions in hospital are still capacity-based and subject to the core provisions of the Act

BOX 1 Mental Capacity Act (Northern Ireland) 2016: principles and main Part 2 provisions

\section{Principles}

- The avoidance of making undue assumptions about capacity (s.1(3)(b))

- Supportive decision-making measures (s. 1(4))

- Upholding the right to make an unwise decision (s. 1(5))

- That any act done on behalf of a person lacking capacity must be in the person's best interests (s. 2(2))

Part 2 provisions

- Deprivation of liberty of a person (s. 24)

- Involuntary treatment of a person who lacks capacity (s. 28)

- Protection from liability (ss. 9-10)

- Additional safeguards, including:

- second opinions (ss. 16-18)

$\circ$ authorisations (ss. 19-20)

- mental capacity advocacy (s. 35)

- rights of review (ss. 45-53)
BOX 2 Mental Capacity Act (Northern Ireland) 2016: main criminal justice provisions in Part 10

- Court powers to remand an accused person to hospital (s. 162)

- New disposal options, including:

- public protection orders (s. 167)

$\circ$ interim detention orders (s. 177)

- supervision and assessment orders (Schedule 7)

- powers to transfer prisoners requiring treatment to hospital (ss. 211-225)

(s. 243). These provisions will come into operation on date to be set by the Department of Health for Northern Ireland (s. 307), which will also produce a Code of Practice (s. 288).

\section{Key definitions}

\section{Disorder}

Part 10 of the MCA(NI) makes reference to 'a disorder' in the criteria for the provisions of remand to hospital and the making of a supervision and assessment order. In s. 252(1) it sets out this definition:

“"disorder" (without more) includes any disorder or disability, whether mental or physical'.

This definition is specific to Part 10 and to be distinguished from 'mental disorder', which is defined in s. 305 as 'any disorder or disability of the mind'.

\section{Disorder requiring treatment}

'[A] disorder requiring treatment' forms part of the entry criteria for a remand to hospital, a hospital direction and a transfer order. A disorder requires treatment 'if it, or any of its symptoms or manifestations, could be alleviated or prevented from worsening by treatment' (s. 252(2)).

\section{An impairment of, or disturbance in the functioning of, the offender's the mind or brain}

This criterion is a requirement for the new provisions of public protection order, public protection order with restrictions, and interim detention order.

The new criteria of 'a disorder', 'a disorder requiring treatment' and 'an impairment of, or disturbance in the functioning of, the offender's mind or brain' (all of which are interpreted in s. 252) replace the previous diagnostic terms 'mental illness' or 'severe mental impairment' found in the Mental Health (Northern Ireland) Order 1986 (MH(NI)O) Part 3. Furthermore, the $\mathrm{MH}(\mathrm{NI}) \mathrm{O}$ also contained 
a general exclusion for personality disorder and dependence on alcohol or drugs (Article 3(2)). The only exclusion in the MCA(NI) is for dependence on alcohol or drugs in the meaning of 'mental disorder' (s. 305(2)).

There is, therefore, a significant broadening of the scope of the legislation in diagnostic terms, to include, for example, personality disorder, attention-deficit hyperactivity disorder (ADHD), neurodevelopmental disorders, and intellectual disability of any severity. The scope is broadened beyond the realms of mental disorder to include illnesses and disorders found in other medical settings. The criterion of 'an impairment of, or disturbance in the functioning of, the offender's mind or brain' could, in theory, be used to include disorders outwith recognised diagnostic categories, as there is no requirement that the disturbance in functioning of the mind must have arisen from a recognised medical condition.

\section{Lacks capacity}

A lack of capacity coupled with a 'best interests' assessment forms the basis for involuntary treatment and other provisions of the Act. The definition of 'lacks capacity' is similar to that found in s. 3 of the Mental Capacity Act 2005, albeit with some important differences. A similar approach of a diagnostic threshold and a functional test of information processing are used in the meaning of 'lacks capacity'. The diagnostic threshold in the MCA(NI) is broad, including a statement that it does not matter if caused by a disorder, a disability or otherwise (s. 3(3)). The functional test of information processing in decision-making ability includes an 'appreciation element'. That is, that the person is "not able to appreciate the relevance of that information and to use and weigh that information' (s. 4). The addition of an appreciation element alters the test of capacity to include complex and subtle impairments of decision-making found, for example, as a result of delusions or loss of insight. It is therefore likely to broaden the meaning of 'lacks capacity', particularly among those with mental illnesses. The test of capacity could be especially medically defined where an impairment in the appreciation element is due to mental illness, as the doctor will be required to make a value judgement on what is most relevant to a decision, for example when weighing risk to life against deprivation of liberty.

The shift to 'appreciation' finds a parallel in the evolution of the insanity defence, where the narrowly cognitive test of 'knowledge' has been replaced by 'appreciation' (Rix 2016) in several jurisdictions, including Northern Ireland, which achieved this modernisation 50 years ago (see below).

\section{Unfitness to be tried and insanity}

The legal test of unfitness to plead remains that of the common law test formulated in $R \mathrm{v}$ Pritchard (1836) following the case of $R v$ Dyson (1831) (Rix 2012) and developed in $R$ v M (John) [2003]. The Northern Ireland Law Commission (2013) has recommended that the 'Pritchard test' is updated to incorporate the language of capacity. The Law Commission for England and Wales (Law Commission 2016) has also proposed a capacitybased test for unfitness to plead and putting it on a statutory basis.

Section 206 allows the court to find a person not guilty by reason of insanity on the evidence of two medical practitioners, including the oral evidence of one AMP (s. 206(3)).

The test of insanity remains that of the Criminal Justice (Northern Ireland) Act 1966, which states at s. 1 that:

“"insane person” means a person who suffers from mental abnormality which prevents him -

(a) from appreciating what he is doing; or

(b) from appreciating that what he is doing is either wrong or contrary to law; or

(c) from controlling his own conduct; and "insanity" shall be construed accordingly'.

This test is arguably closer to what 'the M'Naghten rules' (M'Naghten's Case (1843)) were meant to express and it is therefore broader than the interpretation adopted by the Court of Appeal in England and Wales (Rix 2016). Significantly, it uses the term 'appreciate' instead of 'know', it makes explicit that appreciating the wrongfulness of the conduct can found the defence even if there is appreciation of its unlawfulness, and its 'conduct' element also makes it a defence of wider application.

The range of disposals following a finding of unfitness to be tried or insanity has changed. The court must make a PPOR, a PPO without restrictions, a supervision and assessment order or an absolute discharge if there are findings of unfitness to be tried or not guilty by reason of insanity (s. 207). If the offence charged is one for which the penalty is fixed by law the only disposal open to the court is a PPOR (s. 207(b)) and it cannot be for a specified period (s. 207(c)).

\section{Disposal options}

\section{Remand to hospital}

Section 162 allows remand of an accused person to hospital if they would otherwise be remanded in custody and the conditions for remand to hospital are met. The conditions for remand to hospital are 
the 'medical report condition' (s. 164(1)) and/or the 'treatment condition' (s. 165(1)).

The 'medical report condition' is that the court is satisfied, on the basis of medical evidence, that the accused has, or there is reason to suspect has, 'a disorder' (s. 164(1)(a)), that a report should be made into the accused's mental or physical condition (s. 164(1)(b)), that an assessment for the purposes of the report would be impracticable in custody (s. 164(1)(c)) and that it would be practicable to assess the person in hospital (s. 164(1)(d)).

The medical evidence required by the court is the oral evidence of an approved medical practitioner (AMP) in cases of mental disorder (s.164(3)(a)) or otherwise a medical practitioner with special experience in the diagnosis or treatment of the (physical) disorder (s. 163(3)(b)). Further remands beyond 28 days (s. 162(5)) will be on the basis of the oral or written evidence of the medical practitioner in charge of the person's hospital care (s. 164(4)).

The 'treatment condition' is that a person has 'a disorder requiring treatment', that failure to provide in-patient treatment would 'more likely than not' result in 'serious physical or psychological harm' to the accused person or 'serious physical harm' to other persons, and that remanding to hospital would be likely to result in significantly better clinical outcomes (s. 165(1)).

The terminology 'more likely than not' would seem to indicate a legislative intention to adopt the civil standard of proof, i.e. the balance of probabilities. This would therefore appear to improve on the rather variable interpretation of the 'substantial likelihood' terminology of the $\mathrm{MH}(\mathrm{NI}) \mathrm{O}$, which in relation to risk assessment was interpreted in $R e J R 45$ Application (2011), but later interpreted by the Northern Ireland Court of Appeal in $R \mathrm{v}$ Hackett [2015] as amounting to an 'evaluative judgement' with regard to both likelihood and severity.

The court will consider whether treatment is available (s. 165(2)(b)) and possible either with consent (s. 165(2)(c)(i)) or under Part 2 (s. 165(2)(c)(ii)). The evidence of two medical practitioners will be required, one of whom must be an AMP in cases of mental disorder (s. 165(3)).

Under the MCA(NI) an accused can be remanded to hospital for a report not just because they have a disorder but also if a disorder is merely suspected.

The requirement for oral medical evidence (except for the extension of the remand period) is retained and so, unlike in the equivalent provision of s. 35 (3)(a) of the Mental Health Act 1983 (covering England and Wales), which allows for written or oral medical evidence, the safeguard for the accused is that the reporting medical practitioner is required to attend court where, if so desired, the recommendation can be challenged.
There is a notable and possibly unfortunate absence of reference to risk of psychological harm to others. This element of risk to others is particularly relevant in domestic violence, sexual violence and stalking.

\section{Public protection order}

Public protection orders (PPOs) replace hospital orders. Section 167 allows the court to make a PPO without restrictions in cases of imprisonable offences (other than those for which the sentence is fixed by law, i.e. murder) if the detention conditions are met. The court may make a public protection order with restrictions (PPOR) if the detention conditions and restriction conditions are met. In a court of summary jurisdiction a PPO can also be made without recording a conviction if the court is satisfied that the person did the act or made the omission charged and the offence is an imprisonable offence other than one with a fixed sentence (s. 209).

A PPO without restrictions requires that the offender is admitted to and detained in an appropriate establishment (s. 167(3)), whereas a PPOR requires that the offender is admitted to and detained in an appropriate establishment for either a specified or an unlimited period (s. 167(4)).

\section{The detention conditions}

The detention conditions include a requirement for written or oral medical evidence of at least two medical practitioners, including the oral evidence of an AMP (s. 168(5)) to the effect that there is 'an impairment of, or disturbance in the functioning of, the offender's mind or brain' (s. 168(2)(a)), that 'appropriate care or treatment is available' (s. 168 (2)(b)), that dealing with the person without detention 'would create a risk, linked to the impairment or disturbance, of serious physical or psychological harm to other persons' (s. 168(2)(c)) and that depriving the person of their liberty would be a proportionate response to the likelihood and seriousness of the harm (s. 168(2)(d)).

The requirement for oral medical evidence, as in the previous legislation, affords a safeguard for the accused in that the reporting medical practitioner is required to attend court, where, if so desired, the recommendation can be challenged; this is in contrast to the equivalent provision of s. 37 of the Mental Health Act 1983 (for England and Wales), which allows for written or oral medical evidence. The requirement to have regard separately to both the likelihood of harm and the seriousness of that harm (s. 168(2)(d)(i)) avoids the difficulty resulting from s. 41 of the Mental Health Act 1983, where the reference to protecting the public from serious harm has led some judges into the trap of making 
a restriction order in cases where there is a serious risk of harm rather than a risk of serious harm (Rix 1999). The addition of the risk criterion of psychological harm to others will allow detention under a PPO in cases such as domestic violence, sexual offending and stalking.

The court must also be satisfied that making the order is the most suitable way of dealing with the case, having regard to other available ways of dealing with the offender, the nature of the offence, the history of the offender, and the risk of physical or psychological harm to others if the offender were at large (s. 168(3)).

The court must also consider whether a sexual offences prevention order or violent offences prevention order would be more appropriate (s. 168(4)).

\section{The restriction conditions}

The restriction conditions are that the court is satisfied, having regard to all of the circumstances and particularly the nature of the offence, the history of the offender and the risk of physical or psychological harm to the public, that restrictions are necessary for the protection of the public from serious physical or psychological harm (s. 169). They therefore differ from those in Article 47 of the $\mathrm{MH}(\mathrm{NI}) \mathrm{O}$, which are now repealed.

\section{Hospital direction}

Section 174 allows the court to direct detention to hospital on conviction of an imprisonable offence (other than one for which the sentence is fixed by law) if the offender has 'a disorder requiring treatment', failure to provide the treatment would 'more likely than not' result in serious physical or psychological harm to self or serious physical harm

BOX 3 Mental Capacity Act (Northern Ireland) 2016, Schedule 7: requirements for a supervision and assessment order

The following four requirements must be met:

- the person has, or there is reason to suspect that they have, a disorder

- examination is necessary or desirable to assess whether the disorder requires treatment and/or whether the person will consent to treatment or treatment can be given under Part 2 (on the basis of incapacity to consent)

- a supervision and assessment order is desirable in the interests of securing rehabilitation or protecting the public from serious harm from the person or preventing the person committing further offences

- a supervision and assessment order is the most suitable means of dealing with the person to other persons, and appropriate hospital treatment is available (s. 174(2)).

The Department of Justice may terminate a hospital direction and return the person to prison if it receives the 'relevant notification' from a suitable medical practitioner (an AMP in the case of mental health patients) (s. 198(2)).

The 'relevant notification' is to the effect that the person no longer has the disorder (s. 198(4)(a)), or that no effective treatment can be given (s. 198(4) (b)), or that returning the person to prison would 'more likely than not' result in no 'serious psychological or physical harm' to the person or 'serious physical harm to other persons' as a result of not receiving hospital treatment (s. 198(4)(c)).

\section{Interim detention order}

The court may make an interim detention order where it is satisfied that there is 'an impairment of, or disturbance in the functioning of, the offender's mind or brain', that appropriate hospital treatment is available and that there is a reasonable prospect of making a PPO or imposing a custodial sentence with hospital direction (s. 177).

\section{Restraining order}

Section 210 amends the Protection from Harassment (Northern Ireland) Order 1997 to allow a restraining order to be made where a person is unfit to be tried or subject to a PPO. A restraining order may be made to prevent conduct which amounts to harassment or will cause a fear or violence.

\section{Transfer from prison etc. to hospital}

The Department of Justice may transfer a prisoner to hospital if it is satisfied, on the report of at least two medical practitioners: that the person has 'a disorder requiring treatment'; that failure to provide treatment would be 'more likely than not' to result in serious physical or psychological harm to the person or serious physical harm to another person; and that appropriate treatment is available in hospital (s. 212).

The Department of Justice must consider how likely it is that consent for treatment will be given or that treatment will be possible under Part 2 of the MCA(NI) (s. 212(3)(b)).

Civil prisoners and immigration detainees may also be transferred to hospital (s. 214).

\section{Supervision and assessment order}

Supervision and assessment orders replace supervision and treatment orders. A supervision and assessment order can be made only if the four 
requirements set out in Box 3 are met (Schedule 7, para. 2).

Supervision and assessment orders consist of a 'supervision element' and an 'assessment element'. There may also be a 'residence element'.

The 'supervision element' is supervision by a supervising officer (an approved social worker or probation officer) for a period of between 6 months and 3 years (Schedule 7, para. 3).

The 'assessment element' is attendance at a specified place and time for assessment 'by or under the direction of a medical practitioner' of any or all of the following: the supervised person's condition, whether the disorder requires treatment and whether treatment can be provided either with consent or under Part 2 (Schedule 7, para. 4).

A 'residence element' may require the person to reside at a specific place, not including a hospital or care home (Schedule 7, para. 5).

Schedule 7, paragraph 3 requires that the supervised person must comply with the assessment element and any residence element. They must keep in touch with the supervising officer in accordance with any instructions the latter gives. They must notify the supervising officer of any change of address.

Where the supervised person breaches the conditions of a supervision and assessment order, the court may revoke the order and revisit alternative disposal options, such as a PPO with or without restrictions or an absolute discharge (Schedule 7, para. 13).

The conditions under which a supervision and assessment order can be made differ from those of the previous supervision and treatment order. 'A disorder' replaces 'mental condition'. Supervision and assessment orders will be used for the assessment of the need for treatment, as opposed to their predecessors, which were used as a means of imposing treatment. There is no obligation that the supervised person accepts treatment, as was the case in the previous legislation. However, the provisions to deal with breaches of supervision and assessment orders improve the protection of the public and the supervised person because they afford the opportunity to revisit the alternative disposal options.

\section{Rights of review of detention under Part 10}

A person subject to a PPO with or without restrictions, a hospital direction or a transfer direction can apply to the Tribunal within 6 months of the order being made, and annually thereafter (s. 225); their nominated person may apply on their behalf.

A medical practitioner authorised by the detained person can examine the person for the purposes of advising whether to apply to the Tribunal (s. 227).
The Attorney General, the Department of Health or the Master (Care and Protection) can refer a person for a tribunal hearing at any time (s. 228). This widens the referral from the Secretary of State, to whom it was limited under the $\mathrm{MH}(\mathrm{NI}) \mathrm{O}$ (Article 76).

The Tribunal has the power to discharge or not discharge a person subject to a PPO without restrictions (s. 231).

The Tribunal has the power to discharge, conditionally discharge or not discharge a person subject to a PPOR (s. 232).

The Tribunal may only not discharge a person if the 'prevention of serious harm condition' is met. For those subject to a PPO with or without restrictions, the criteria are: there is an impairment of, or disturbance in the functioning of, the mind or brain; releasing the person would create a risk (linked to the impairment or disturbance) of serious physical or psychological harm to other persons; and a deprivation of liberty is proportionate to the likelihood and seriousness of the risk (s. 233).

The criteria for those subject to hospital directions and hospital transfer directions are different. The Tribunal must satisfy itself that the "prevention of serious harm condition' is met in order to continue the detention. The criteria in these cases are: the person has the disorder for which they were transferred; effective treatment can be given in the hospital; and 'it is more likely than not' that returning the person to prison would result in serious physical or psychological harm to the person or serious physical harm to another person (s. 237).

\section{Conclusions}

There is a long history of reforms in mental health law that have sought to increase patient autonomy. A capacity-based approach for all has repeatedly been proposed over the course of decades, both in the UK and internationally. However, it stumbled at the hurdles of the concerns of legislators about the scope of the legislation and the protection of public safety. The MCA(NI), in repealing mental health legislation and adopting a capacity-based approach to the treatment and protection of all in society, is truly a radical change.

Although the MCA(NI) uses, and impliedly distinguishes between, the 'mental' and the 'physical', it does have the effect, by bringing mental and physical disorders and disabilities within the same piece of legislation, of blurring the distinction and chipping away at the Cartesian mind-body dualism that has in some ways contributed to the separation of mental health provision from mainstream healthcare provision. 
MCO answers

1 e 2 e 3 d 4 d 5 c
The non-discriminatory nature of the entry criteria to the provisions of the MCA(NI) inevitably increases the scope of the legislation. The key definitions for entry into the criminal justice provisions of the Act are vastly more inclusive than those of their predecessors and those found in other jurisdictions. This will allow the inclusion of marginalised groups such as those with a primary diagnosis of personality disorder, thus avoiding the contentious issue of making a distinction between mental illness and personality disorder (Nathan 2016), and those with varying degrees of intellectual disability and behavioural disturbance. The broadening of eligible diagnoses for transfer from prison to hospital could have a significant impact for prisoners, given the high prevalence of mental disorders and comorbidities in that group (Fazel 2012). However, the risk threshold for a person to transfer from prison to hospital is that serious harm to the prisoner or serious physical harm to others must be 'more likely than not'. The same risk threshold is used by the Tribunal to decide whether the transferred prisoner should continue to receive hospital treatment. The impact of this risk threshold on clinical practice remains to be seen.

The scope of the MCA(NI) is further broadened by the inclusion of risk of serious psychological harm to others in some of the provisions. This will serve to protect those at risk from stalking or harassment, and possibly also in cases of domestic violence that has manifested only in emotional or psychological abuse.

The PPO has been regarded as a contentious part of the Act, given that its purpose is to protect the public rather than to serve a health interest. It has thus proved necessary to include a measure aimed at reducing harm 'as a basis for society to take action' even within a fusion law (Gledhill 2010). There is a body of opinion that the circumstances for a PPO are 'extremely limited' (Harper 2016). However, given the broader diagnostic entry criteria than those contained in its predecessors, the range of circumstances in which such an order can be made appears to have increased.

One theoretical area of concerns is how high-risk patients who quickly respond to treatment will be managed, given that the 'nature or degree' of the mental condition is not included in PPO provisions or required to be considered at subsequent Tribunal reviews. It could be the case that whatever 'impairment of, or disturbance in the functioning of, the mind or brain' that made the PPO appropriate is no longer present after a brief period of treatment, even after the most grave offences.

Another potential pitfall is that the criteria for admission to hospital under the criminal justice provisions are based on the presence of a disorder or an impairment or disturbance in functioning, whereas the criteria for involuntary treatment are based on a lack of capacity to consent. This is significant, given that a study of patients with mental illness in a large forensic hospital demonstrated that only $24 \%$ lacked capacity to consent to treatment (Dornan 2015). There is therefore a potential for concerning refusals of treatment.

However, although there are some areas of concern in how the new provisions may operate in practice, the change in the meaning of capacity introduced by the 'appreciation element' could mitigate against some of the potentially negative aspects. The practical impact is likely to be of interest in the consideration of future mental health law reform in other jurisdictions.

\section{References}

Applebaum S (2010) Harnessing the power of fusion? A valiant but flawed effort to obviate the need for mental health law. Journal of Mental Health Law, 20: 25-33.

Burns T (2010) Mental illness is different and ignoring its differences profits no one. Journal of Mental Health Law, 20: 34-9.

Department of Health (1999) Review of the Mental Health Act 1983: Report of the Expert Committee. Department of Health. (http://webarchive.nationalarchives.gov.uk/20120503230453/http://www.dh.gov.uk/ prod_consum_dh/groups/dh_digitalassets/@dh/@en/documents/digitalasset/dh_4062614.pdf)

Dornan J, Kennedy M, Garland J, et al (2015) Functional mental capacity, treatment as usual and time: magnitude of change in secure hospital patients with major mental illness. BMC Research Notes, 8: 566.

Fazel S, Seewald K (2012) Severe mental illness in 33,588 prisoners worldwide: systematic review and meta-regression analysis. British Journal of Psychiatry, 200: 364-73.

Fistein EC, Holland AJ, Gunn MJ (2009) A comparison of mental health legislation from diverse Commonwealth jurisdictions. International Journal of Law and Psychiatry, 32: 147-55

Gledhill K (2010) A model law for fusing incapacity and mental health legislation - a comment on the forensic aspects of the proposal. Journal of Mental Health Law, 20: 47-54.

Harper C, Davidson G, McClelland R (2016) No longer 'anomalous, confusing and unjust': the Mental Capacity Act (Northern Ireland) 2016. International Journal of Mental Health and Capacity Law, 22: 57-70.

Kelly B (2016) Mental IIIness, Human Rights, and the Law. RCPsych Publications.

Law Commission (2016) Unfitness to Plead (Law Com No 364). TSO (The Stationery Office).

Nathan R, Rix KJB (2016) A special case for personality disorder: are the distinctions between personality disorder and mental illness in clinical and legal practice justified? In Legal Perspectives on State Power: Consent and Control (eds C Ashford, A Reed, N Wake): 284-308. Cambridge Scholars Publishing.

Northern Ireland Law Commission (2013) Report: Unfitness to Plead (NILC 16 (2013)). NILC.

Rix KJB, Agarwal M (1999) Risk of serious harm or a serious risk of harm? A trap for judges. Journal of Forensic Psychiatry, 10: 187-96.

Rix KJB (2012) Fitness to plead and fitness to stand trial - Then, now and in the future. Expert and Dispute Resolver, Summer: 16-20.

Rix KJB (2016) Towards a more just insanity defence: recovering moral wrongfulness in the M'Naghten Rules. BJPsych Advances, 22: 44-52.

Scottish Executive (2000) Report of the Committee on Serious Violent and Sexual Offenders. Scottish Executive. 
Scottish Executive (2001) New Directions: Report on the Review of the Mental Health (Scotland) Act 1984. TSO (The Stationery Office).

Szmukler G, Daw R, Dawson J (2010) A model law for fusing incapacity and mental health legislation. Journal of Mental Health Law, 20: $11-24$

Szmukler G, Daw R, Callard F (2014) Mental health law and the UN Convention on the Rights of Persons with Disabilities. International Journal of Law and Psychiatry, 37: 245-52.

United Nations (2006) Convention on the Rights of Persons with Disabilities. United Nations.

\section{Cases}

Banks v Goodfellow (1870) 5 QB 549.

M'Naghten's Case (1843) 10 Cl \& F 200.

Re JR 45 Application (2011) NIOB 17

$R$ v Dyson (1831) 7 C\&P 303.

$R v$ Hackett [2015] NICA 57

$R$ v M (John) [2003] EWCA Crim 3452 CA.

$R v$ Pritchard (1836) 7 C\&P 303.
MCOs

Select the single best option for each question stem

\section{Fusion legislation:}

a increases beneficence at the expense of patient autonomy

b is exemplified by the Mental Capacity Act 2005

c as a recommendation has been accepted by the UK government following the Richardson Committee's review of the Mental Health Act 1983

$\mathrm{d}$ has the disadvantage of discriminating against people with mental disorder

$\mathrm{e}$ is exemplified by the Mental Capacity Act (Northern Ireland) 2016.

2 The Mental Capacity Act (Northern Ireland) 2016:

a avoids the need to consider the effect of making undue assumptions about capacity

b contains a general exclusion of personality disorder from the provisions for involuntary treatment

c sets out new provisions for guardianship orders

d incorporates dependence on alcohol or drugs in the meaning of 'mental disorder'

e extends beyond the realms of mental disorder to include illnesses and disorders found in other medical settings.

\section{About definitions under the Mental Capacity} Act (Northern Ireland) 2016:

a the diagnostic criteria for 'mental illness' are set out

b the effects of prevention are excluded from the definition of 'a disorder requiring treatment'

c there is no distinction between 'disorder' in general and 'mental disorder'

d the definition of lacking capacity incorporates the inability to appreciate the relevance of information

e the definition of 'an impairment of, or disturbance in the functioning of, the offender's mind or brain' includes a requirement that the impairment or disturbance must have arisen from a 'recognised medical condition'

\section{Under the criminal justice provisions of the Mental Capacity Act (Northern Ireland)} 2016:

a an accused can person can be remanded to hospital even if they would not otherwise be remanded in custody

b the detention conditions for a public protection order are so defined that it is not necessary to consider whether depriving the person of their liberty would be a proportionate response c written medical evidence is sufficient in a recommendation for a remand to hospital

d the risk of physical or psychological harm to others is a necessary consideration when making a public protection order

e a supervision and assessment order cannot be made if the offender does not accept treatment.

5 Disposal options following a finding of unfitness to plead or insanity in relation to an offence with a penalty that is fixed by law include:

a a public protection order without restrictions

b a supervision and assessment order

c a public protection order with restrictions

d a hospital direction

e an absolute discharge. 